\title{
IDEOLOGIAS, DISCURSOS Y DOMINACION
}

\section{Antonio Ariño Villarroya}

Universidad de Valencia

\section{RESUMEN}

El artículo pretender efectuar una revisión crítica de la prolífica literatura acerca de las ideologías. Se adentra en un campo de las ciencias sociales, especialmente de la sociología de la cultura, en el que abunda el ensayismo y la polisemia léxica, con la intención de imponer rigor analítico. Para ello se construye una tipología de las principales concepciones de la ideología, diferenciando cuatro grandes modelos conceptuales: cognitivo-crítico, político-crítico, político-neutro y cognitivo-neutro o semiótico. Se describe y examina cada una de estas concepciones. Y, finalmente, se opta por una concepción político-crítica, que restringe el campo de acción del análisis de la ideología a los procesos de utilización de las formas simbólicas en contextos de dominación y con propósitos de legitimación. Esta concepción implica a su vez una redefinición de conceptos como discurso, cosmovisión y narrativa.

\section{EL PLANTEAMIENTO DEL PROBLEMA: QUE ES LA IDEOLOGIA}

«La ideología ha llegado a ser hoy, y por buenas razones, un término irremediablemente caído.» Según la categórica sentencia de Bell, «la ideología es una palabra en desuso" (1992: 453). En una época de rampante pragmatismo, se ha convertido en un término caduco. Por su parte, Baudrillard, y con él el postestructuralismo, sostienen que donde imperan los simulacros, no hay lugar para la ideología (ver Larrain, 1994: 110).

Pero, curiosamente, un simple repaso a los numerosos títulos de publicacio- 
nes que han aparecido en los últimos veinticinco años y que incluyen el término ideología o el derivado ideológico en el enunciado del titular obliga a poner en entredicho dicha conclusión: al menos en ese sentido, no ha habido un fin de las ideologías. Algunos de estos titulares son sorprendentes, como, por ejemplo, Relaciones laborales en empresas ideológicas, La afasia y la polarización ideológica en torno al sistema nervioso central en la primera mitad del siglo XIX o El marxismo, ideología fría. Unos pocos están dedicados a la pura teoría y al debate escolástico. La gran mayoría se centran en el estudio de las ideologías en campos tan dispares como la política, el derecho, la lengua o los medios de comunicación, y por el tenor del enunciado intuimos que asumen un concepto crítico. Sucede de forma similar con un cuarto grupo que se centra en los «aspectos ideológicos» de ciertas prácticas sociales (desde el fútbol a la domesticidad, pasando por la medicina, el urbanismo, la biología o incluso la física) y donde ideología aparece como sinónimo de discurso en su acepción postestructuralista. En cambio, muchos otros manejan un significado más neutro y analizan el sistema de creencias de algún movimiento social específico (anarquismo, blasquismo, islamismo). En unos pocos casos, finalmente, una somera comprobación del contenido nos induce a pensar que la inclusión del término en el título obedece a razones estéticas, cuando no pura y falazmente comerciales.

Tras esta mirada panorámica, no es posible evitar una impresión de caos lingüístico, de confusión babélica. Por si fuera poco, en la vida cotidiana y la lucha política, ideología funciona como arma arrojadiza para sellar las opiniones del adversario con el estigma de la irracionalidad. Esta situación ha llevado a algunos autores a reconocer que nos hallamos ante el vocablo que "ha suscitado más dificultades» en las ciencias sociales (Abercrombie et al., 1987: 213; Lewins, 1989: 679; Boudon, 1989: 17; McLellan, 1995: 1). Tomarlo como objeto de análisis puede ser tan temerario y peligroso como adentrarse por un campo minado, pero en la medida en que el estudio de la vida social pretenda ser científico habrá de asumir un uso más estricto, riguroso y preciso de su léxico. Por este motivo, nos sentimos obligados a reflexionar sobre su validez como herramienta teórica.

Comenzaremos nuestra argumentación abordando la complejidad del problema con un ejemplo tomado de las representaciones sociales sobre el trabajo. En la sociedad feudal fue usual legitimar el significado y relevancia de éste recurriendo a referencias bíblicas como el exemplum de Marta y María y la expulsión del Paraíso. Según la enseñanza que se extraía de ellas, el trabajo era un castigo acarreado por el pecado original y la devoción debía anteponerse a la obligación. ¿En qué sentido podríamos afirmar que esta imagen es ideológica?, ¿en tanto que constituye una visión del mundo operante en una sociedad determinada?, ¡en tanto que consiste en una representación falsa del trabajo manual como castigo, al atribuir el sudor y el esfuerzo a una sanción divina?, o ¿en tanto que legitima la posición social preeminente del clero y la nobleza en la sociedad estamental?

En el seno del feudalismo surge la burguesía. Esta clase tiene una experien- 
cia completamente distinta de la actividad productiva: el trabajo, duro y esforzado, permite ascender en la escala social e incluso lograr el cielo. Para ella, el mérito no radica en la devoción y mucho menos en el ocio. Así se forja una nueva representación social: el trabajo es vocación, virtud, actividad esforzada, creativa y libre, que siempre encuentra su recompensa. Esta nueva representación corresponde a la experiencia social y religiosa de determinados estratos o grupos sociales ascendentes y, por tanto, es verdadera, ya que constituye una definición de su situación. Pero cuando esta clase social trate de configurar la sociedad en función de sus intereses y para ello necesite universalizar su sistema de valores, variará la función de dicho esquema mental. La idea de que el trabajo es una virtud hará frente a la necesidad de disciplinar a los viejos campesinos convertidos en nuevos asalariados, y la de que es creatividad servirá de base para la implantación del derecho a la libertad de los intercambios en el mercado. Por tanto, la universalización de estos valores (deber profesional y contrato libre) tiene «una significación constitutiva» — como dijera Weber-y aparece como un requisito del sistema capitalista e industrial en sus primeras fases.

Frente a esta concepción, que reifica la historia al proclamar la sociedad liberal como reino de la libertad, se yergue la representación marxiana. El trabajo en la sociedad capitalista es alienación y explotación. El trabajador no trabaja en uso de su capacidad creativa, sino por necesidad: de otro modo se moriría. La libertad formal de los trabajadores en el mercado enmascara la naturaleza desigual del poder económico que obliga al trabajador a vender su fuerza de trabajo. Dados estos planteamientos, si partimos de que la ideología es el sistema de creencias que legitima la dominación, la visión marxiana no sería ideológica, sino teoría crítica de la ideología y, por ende, de la dominación. Pero ¿y si definimos la ideología como un sistema de creencias que legitima intereses particulares, intereses de clase? Sin duda, entonces, de acuerdo con Mannheim, el marxismo sería una ideología más.

En fin, sistema de ideas falsas, ilusorias o erróneas; sistema de ideas que legitiman la dominación; sistema de ideas que representan intereses, visión del mundo, ¿con qué definición podemos quedarnos? Para hallar respuestas que aúnen el rigor analítico y la fuerza argumentativa deberíamos revisar, en primer lugar, la historia del término y proceder, después, a un análisis sistemático de sus usos. Dada la limitación del espacio, reduciremos el primer aspecto a un breve esbozo y nos centraremos en el segundo.

\section{LOS AVATARES DEL TERMINO IDEOLOGIA}

De hecho, la historia del término ideología (véanse Lichteim, 1972; Thompson, 1984 y 1992; Vincent, 1992; Bell, 1990; McLellan, 1995) puede resumirse sucintamente afirmando que parece la evolución de un neologismo a la deriva, pero cuando se la examina de cerca observamos la presencia de cierta lógica subyacente. Con él se trató de designar, en primer lugar, «la ciencia de la formación 
natural de las ideas», una disciplina positiva, útil y susceptible de rigurosa exactitud; después, pasó a nombrar el proceso de legitimación simbólica de la dominación; seguidamente, los sistemas de creencias mediante los cuales se representan intereses sociales y se motiva a los sujetos humanos para la acción colectiva (determinación social) y, finalmente, cualquier visión del mundo. Para Destutt de Tracy, encarnaba el proyecto de la razón ilustrada, pero Napoleón primero, el movimiento reaccionario de De Bonald y Chateaubriand después, y luego el marxismo, identificarían la ideología con una doctrina abstracta y especulativa, divorciada de la realidad. Este concepto de un conocimiento distorsionado, errado, persiste en Mannheim, pese a su intento de fundar una concepción no valorativa. Y se reproduce también en los teóricos del fin de las ideologías, que la definen como una forma de simplificación, de engaño, una redecilla que envuelve a las personas y hace opaco el resto del mundo. Justamente, por las mismas fechas, pero completamente al margen de ese debate, autores como Lenski y C. Geerzt acuñan un concepto estrictamente neutro y general.

Geertz publica en 1964 su conocido e influyente artículo «La ideología como sistema cultural», y Lenski, Poder y privilegio en 1966. Curiosamente, en sus obras no hay referencias cruzadas, pero su visión es muy similar. Lenski, influido por Mosca, quien sostenía que la clase dominante siempre tiende a justificar su poder apoyándose en mitos y creencias y que no se puede regir una sociedad ni cimentar poderosamente su unidad sin alguna "gran superstición» o «ilusión general» (véase Mosca, 1984), considera necesarias las ideologías para la justificación moral del ejercicio del poder, una estrategia eficaz para transformar la simple fuerza en derecho, para proporcionar un aura de legitimidad al privilegio (Lenski, 1969). En Human Societies, publicado en 1970, no sólo acuña un concepto neutro, sino también general: la ideología no es más que la información utilizada para interpretar la experiencia y ordenar la vida social.

Idéntico es el planteamiento de Cliford Geertz, aunque con mayor fundamento teórico. Para Geertz, las concepciones que identifican la ideología con «patologías» comparten una teoría del lenguaje muy deficitaria, al reducirlo a una función meramente pictórica y reproductora de la realidad. La metáfora se caracteriza, nos dice Geertz, porque transgrede las significaciones corrientes y literales y, por tanto, extiende el lenguaje al ampliar su alcance semántico y «suele ser más efectiva cuanto más falsa es». Del mismo modo, el símbolo o las figuras ideológicas derivan su fuerza de «la capacidad de aprehender, formular y comunicar realidades que se sustraen al templado lenguaje de la ciencia» (1987: 184). De aquí su definición de ideologías: éstas son «mapas de una realidad social problemática y matrices para crear una conciencia colectiva». Las ideologías desempeñan la función de "definir (u oscurecer) las categorías sociales, estabilizar (o perturbar) las expectativas sociales, mantener (o minar) normas sociales, fortalecer (o debilitar) el consenso social, y aliviar (o exacerbar) tensiones sociales» (1987: 178). La ideología no es, pues, la contrafigura de la ciencia. Más bien, una y otra son dos estrategias simbólicas diferentes que pueden adoptarse legítimamente ante una misma situación: la ciencia tiende a ser 
la dimensión crítica de la cultura, el diagnóstico, mientras que la ideología es la dimensión apologética o legitimadora. De esta forma, se alcanza una concepción no valorativa de la ideología entendida como sistema de creencias para la interpretación del mundo.

En síntesis, el resultado que nos arroja la historia del término es la convivencia de cuatro conceptos básicos, cuya formulación no ha sido caprichosa, sino que se halla vinculada a determinados procesos típicos de las sociedades modernas: la necesidad de conocimiento fiable; la necesidad de legitimación de una dominación que no puede basarse ya en la fuerza descarnada ni en la apelación a la divinidad; la necesidad de movilización simbólica para la acción social, y la comprensión de la pluralidad de universos simbólicos propia de las sociedades complejas. Pero si bien, como vemos en la figura 1, ésta ha sido la forma de evolución histórica del concepto, un análisis sistemático muestra que el orden lógico invierte el orden histórico: para poder hablar de distorsión (o de validez lógica) y de legitimación de privilegios (o de eficacia social) es preciso reconocer antes su función significante. Lo sorprendente es que para designar las cuatro problemáticas haya sido utilizado el mismo término de ideología.

\section{FIGURA 1}

Esquema evolutivo de las concepciones de la ideología

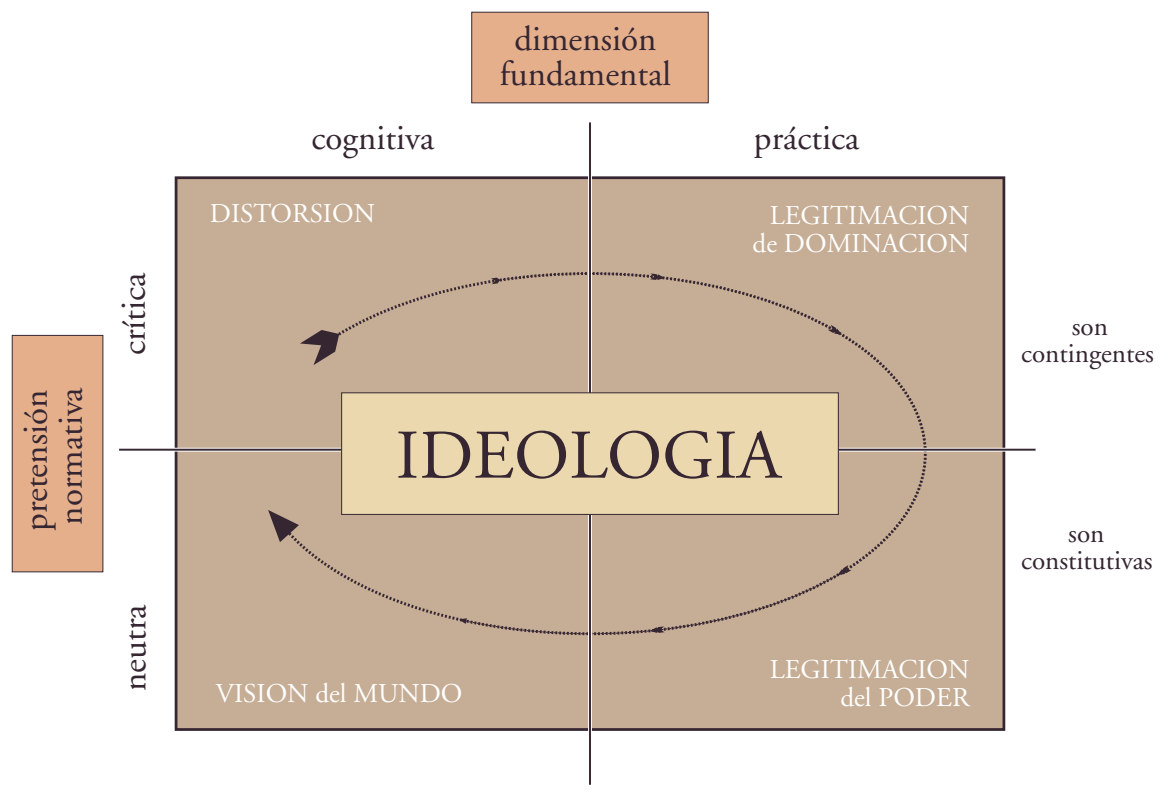




\section{CUADRO 1}

\section{Las teorías de la ideología}

\begin{tabular}{|c|c|c|c|c|c|}
\hline Definición & $\begin{array}{c}\text { Elemento } \\
\text { clave }\end{array}$ & Extensión & $\begin{array}{l}\text { Pretension } \\
\text { normativa }\end{array}$ & $\begin{array}{c}\text { Ubicación } \\
\text { teórica }\end{array}$ & $\begin{array}{c}\text { Corrientes } \\
y \text { autores }\end{array}$ \\
\hline
\end{tabular}

\section{A) Cognitiva critica}

\begin{tabular}{|c|c|c|c|c|c|}
\hline $\begin{array}{l}\text { Falsa conciencia, } \\
\text { prejuicio, } \\
\text { irracional, } \\
\text { simple, } \\
\text { dogmatismo, } \\
=/=\text { ciencia }\end{array}$ & $\begin{array}{l}\text { Carácter ilusorio } \\
\text { Patogenia del } \\
\text { pensamiento } \\
\text { Distorsión } \\
\text { <dimensión } \\
\text { cognitiva> }\end{array}$ & $\begin{array}{l}\text { Restrictiva } \\
\text { «ólo un tipo } \\
\text { de creencias } \\
\text { son } \\
\text { ideológicas» }\end{array}$ & $\begin{array}{l}\text { Crítica } \\
\text { Depurar }\end{array}$ & $\begin{array}{l}\text { Epistemología } \\
\text { Sociología del } \\
\text { conocimiento }\end{array}$ & $\begin{array}{l}\text { Ilustración } \\
\text { Engels y Lukács } \\
\text { Mannheim } \\
\text { Funcionalismo } \\
\text { T. Geiger } \\
\text { K. Popper } \\
\text { Althusser } a \\
\text { Bell }\end{array}$ \\
\hline
\end{tabular}

\section{B) Politica crítica}

\begin{tabular}{|c|c|c|c|c|c|}
\hline $\begin{array}{l}\text { Sistema de } \\
\text { ideas que } \\
\text { legitiman la } \\
\text { dominación }\end{array}$ & $\begin{array}{l}\text { Función } \\
\text { legitimante } \\
\text { <dimensión } \\
\text { práctica> }\end{array}$ & $\begin{array}{l}\text { Restrictiva } \\
\text { condicional } \\
\text { "Todos los sist. } \\
\text { de creencias } \\
\text { pueden ser } \\
\text { ideológicos» }\end{array}$ & $\begin{array}{l}\text { Crítica } \\
\text { Emancipar }\end{array}$ & $\begin{array}{l}\text { Teoría del } \\
\text { poder }\end{array}$ & $\begin{array}{l}\text { Marxismo } \\
\text { E. Frankfurt } \\
\text { Bourdieu } \\
\text { Giddens } \\
\text { J. B. Thompson } \\
\text { K. Thompson } \\
\text { Fairclough } \\
\text { Larrain }\end{array}$ \\
\hline C) Politica neutra & & & & & Lenin \\
\hline $\begin{array}{l}\text { Sistema de } \\
\text { ideas que } \\
\text { legitiman } \\
\text { el poder }\end{array}$ & $\begin{array}{l}\text { Función } \\
\text { legitimante } \\
\text { de cualquier } \\
\text { poder }\end{array}$ & $\begin{array}{l}\text { Universal } \\
\text { tendencial } \\
\text { «Son ideológicas } \\
\text { todas las } \\
\text { creencias que } \\
\text { legitiman } \\
\text { el poder» }\end{array}$ & Neutra & $\begin{array}{l}\text { Teoría del } \\
\text { poder }\end{array}$ & $\begin{array}{l}\text { Gramsci } \\
\text { Althusser } b \\
\text { Anál. discurso } \\
\text { Laclau, S. Hall } \\
\text { Therborn } \\
\text { C. Bell, R. Wilson } \\
\text { Vincent, Reboul } \\
\text { Seliger, Gouldner } \\
\text { Rudé et al. }\end{array}$ \\
\hline
\end{tabular}

D) Semiótica neutra

$\begin{array}{llll}\text { Visión del } & \text { Función } & \text { Inclusiva } & \text { Neutra } \\ \text { mundo o } & \text { significante } & \text { Teoría de } & \text { Geertz } \\ \text { sistema de } & & \text { la cultura } & \text { Dupont } \\ \text { creencias } & & & \text { Castoriadis } \\ & & & \text { Abercrombie } \\ & \text { es ideología» } & & \text { Wuthnow } \\ & \text { Es necesaria } & & \text { Fenomenología } \\ & \text { e inevitable } & & \text { Ha. Mentalidades } \\ & \text { Universal y } & & \text { Represt. Sociales } \\ & \text { constitutiva } & & \text { Anal. discurso }\end{array}$




\section{UN MAPA SISTEMATICO DE LAS DEFINICIONES DE LA IDEOLOGIA}

\section{Definición cognitiva critica: la ideología como contrafigura de la ciencia}

Los autores que hemos agrupado en este campo conceptual identifican la ideología con un sistema de falsas creencias. El elemento clave de la definición es, por tanto, el carácter ilusorio o, si se prefiere, patológico del pensamiento. Para unos, falsedad equivale simplemente a error o mentira; para otros, la falsedad radica en confundir juicios de valor con juicios de hecho; y mientras los funcionalistas sostienen que las ideologías son irracionales y dogmáticas y toman como ejemplos el fascismo y el marxismo, parte de la tradición marxista afirma que son ilusorias y enmascaradoras y se centran, ante todo, en el análisis de la teoría económica liberal y del mercado.

Esta concepción es restrictiva: «sólo un tipo determinado de creencias son ideológicas». No todo el conocimiento es patológico. El análisis de la ideología se entiende como un instrumento crítico o evaluador; se pretende depurar las representaciones, las creencias y el lenguaje para lograr conocimiento fiable. Su locus propio es la epistemología más que la sociología, puesto que se preocupa, ante todo, por la validez lógica de los sistemas de conocimiento.

Dos críticas fundamentales se le han dirigido. La primera ataca su modelo de ciencia (Dumont, 1974; Vincent, 1992); la segunda, su énfasis en la validez lógica. Esta conceptualización distingue radicalmente entre creencias y conocimiento verdadero o científico. "Si no existiera, al menos teóricamente, la posibilidad de proposiciones por completo adecuadas a la realidad, el concepto de ideología carecería de sentido", afirma Geiger (1972: 14). Ahora bien, ya Weber había señalado que no hay fundamentación científica para el conocimiento científico, que el criterio de verdad depende de su significación cultural, que conocer es seleccionar y que toda selección conlleva simplificación. Al estar fundada en una distinción radical entre realidad e ideas, ignora en qué medida la realidad es ya para los seres humanos un dominio preinterpretado, que no existe la transparencia del lenguaje y, por tanto, que éste no es un mero instrumento de representación.

Pero, además, se han planteado objeciones que, obviando el problema epistemológico, propugnan una definición alternativa de ideología. La crítica procede, en primer lugar, de la tradición irracionalista decimonónica (Nietzsche, Mosca, Pareto o Sorel), según la cual las ideas falsas e irracionales también pueden ser útiles para el poder o la vida o, como señala Boudon (1989), son racionales subjetivamente (se las profesa por buenas razones). Además, como nos han enseñado Adorno, Marcuse, Foucault o Habermas, la ciencia y la técnica pueden operar como ideologías, en el sentido de enmascarar la dominación. Tanto la vieja ideología del «libre contrato» como la nueva ideología de la "conciencia tecnocrática» — nos dirán— son ideologías porque sirven para impedir la tematización de los fundamentos sobre los que está organizada la vida social. De esta forma, hemos dado el salto al segundo modelo analítico. 


\section{Definición politico-critica: la ideología como legitimación de la dominación}

De acuerdo con ella, no existen sistemas de creencias que sean per se, intrínsecamente, ideológicos. La ideología es aquel aspecto o característica de los sistemas de significado que sirve para legitimar la dominación, para sostener el privilegio. Coinciden en este concepto determinadas corrientes del marxismo, igualmente sociólogos críticos como Bourdieu, Giddens, J. B. Thompson, K. Thompson, Fairclough o McLellan, y autores más difíciles de clasificar como Lenski. Por ello mismo, sería un error imputar esta conceptualización en exclusiva al marxismo. Al respecto resulta muy ilustrativo el siguiente texto de Gaetano Mosca:

"Con frecuencia las aristocracias se han envanecido de un origen sobrenatural o al menos diferente y superior al de la clase gobernada. Tal pretensión se explica por un hecho social importantísimo [...] que hace que toda clase gobernante tienda a justificar su poder de hecho, apoyándose en un principio moral de orden general. Pero recientemente la misma pretensión se presentó con apoyo de un equipo científico: algunos escritores, desarrollando y ampliando las teorías de Darwin, creen que las clases superiores representan un grado más elevado de evolución social, y que por lo tanto ellas son mejores que las inferiores por constitución orgánica. De Gobineau, Gumplowicz y otros van más lejos, y sostienen resueltamente el concepto de que la división de los pueblos en clases profesionales está fundada, en los países de civilización moderna, en una heterogeneidad étnica» (Mosca, 1984: 121-122).

El análisis ideológico no se preocupa por la verdad científica, «más bien observa en qué medida los sistemas de signos y símbolos se hallan implicados en una distribución asimétrica de poder y recursos» (McLellan, 1995: 83; Frow, 1989: 208).

Esta concepción de la ideología implica una teoría conflictiva de la sociedad: ésta es una estructura objetiva en la que existe un reparto asimétrico de los recursos. La dominación consiste en relaciones de poder que son «sistemáticamente asimétricas», basadas en el privilegio y en la posesión de una porción del excedente. Y dado que el privilegio no puede mantenerse durante mucho tiempo fundándose sólo en la violencia física, se requieren también mecanismos de ocultación y formas ideológicas de consentimiento.

Uno de los aspectos más interesantes de esta concepción radica en el análisis de los mecanismos o modus operandi de las ideologías. Rastreando por los distintos autores pueden identificarse muchos de ellos: legitimación (Marx), reificación (Lukács), racionalización (Habermas) interpelación (Althusser), unificación, etc. (ver especialmente Thompson, 1990; Larrain, 1994, y Newman, 1995). Tan sólo pondremos un ejemplo. Lenski encuentra en la estrategia de la universalización una forma de legitimación de los intereses particula- 
res de la clase dominante: "Hay buenas razones — nos dice- para creer que, a lo largo de la historia, en muchas sociedades los intereses de sólo una pequeña minoría de sus integrantes estuvieron identificados de modo significativo con los de la sociedad total.» $\mathrm{Y}$ en otro pasaje afirma que los miembros de las clases políticamente dominantes tienen más facilidad que los de otras clases para "reconocer» la convergencia de los intereses del individuo y los de la sociedad ( Lo que es bueno para la General Motors es bueno para el país, y viceversa»). "Las leyes — nos dice - pueden redactarse siempre de manera que favorezcan a cierto segmento particular de la sociedad. Anatole France vio esto con claridad cuando escribió: "En su majestuosa igualdad, la ley prohíbe tanto al rico como al pobre dormir bajo los puentes, pedir limosna en la calle y robar pan"... Las leyes pueden redactarse de tal modo que protejan los intereses de la élite, aunque estén plasmadas en términos muy generales, universalistas» (Lenski, 1969: $49,55$ y 65$)$.

Dos críticas fundamentales se han dirigido a los autores representativos de esta corriente: por un lado, se les acusa de postular un concepto consensual de la dominación; de otro, identifican ideología con intereses de clase, pero sólo atribuyen formaciones ideológicas a la clase dominante.

En relación con la primera crítica, conviene señalar que los autores más recientes que postulan esta definición (Lenski, Thompson, Fairclough, Giddens) no comparten algunos aspectos decisivos de la tesis de la ideología dominante: la concepción de la ideología como dominación no implica a priori la existencia de la ideología dominante ni, menos aún, que ésta sea la única forma de conciencia posible en una sociedad dada.

Se critica la identificación y confusión entre integración social e integración del sistema o, dicho en otros términos, entre orden normativo y orden fáctico. Los teóricos de la ideología dominante tienden a ofrecer "una visión sobreintegrada de la sociedad en la que la ideología forja un total sin fisuras» (Abercrombie et al., 1987: 181), lo que plantea una grave dificultad para explicar el conflicto y las resistencias (Turner, 1980: 78; K. Thompson, 1986; Archer, 1988). Pero, además, la existencia de determinado grado de estabilidad no depende necesariamente de la ideología. De hecho, las clases sociales tienen cosmovisiones que son diferentes y contrapuestas, pero están unidas por una red de relaciones sociales objetivas: la coerción sorda de las relaciones económicas (Marx), la división del trabajo (Durkheim), la naturaleza coercitiva de la ley y la política (Mosca), el hábito y la costumbre (Lenski). Por otra parte, dichas teorías suelen caer en la falacia internalista que implica ignorar que los procesos de recepción y apropiación son inevitablemente una tarea hermenéutica y contextual (K. Thompson, 1992: 352; Fairclough, 1992: 28; Wilson, 1993; J. B. Thompson, 1990 y 1995).

Admitiendo esto, es decir, que todas las clases y grupos sociales tienen una forma de conciencia práctica que no es reductible a una ideología dominante, sin embargo, muchos autores restringen el término ideología para designar solamente el sistema de ideas que conserva y legitima el statu quo y que oculta 
las contradicciones, viéndose obligados a buscar otros términos para designar las formas de la conciencia práctica de los grupos subordinados y de los movimientos de protesta. Sin embargo, en Gramsci, en Althusser y en otros autores encontramos un concepto neutro de ideología como legitimación del poder o como motivación para la movilización a la acción social. Lincoln, por ejemplo, sostiene que «el discurso puede servir también a los miembros de las clases subordinadas en sus tentativas para desmistificar, deslegitimar y deconstruir las normas establecidas, instituciones y discursos que juegan un rol en la construcción de su subordinación» (1989: 4-5). De esta forma, damos el salto a la concepción político-neutra.

\section{Concepción politico-neutra: la ideología como sistema de creencias relativo a la acción sociopolitica}

Al pasar de los campos conceptuales A y B a C y D (ver mapa cognitivo) se produce una ruptura en el tipo de pretensión normativa que rige la conceptualización. Mientras que las dos formas primeras de definición tienen un carácter evaluador, ahora nos introducimos en definiciones asépticas. Ya no cuenta ni la causación social ni la veracidad o falsedad. De esta forma, se rompe con la tradición ilustrada: el sistema de creencias puede ser falso e injusto, pero sigue siendo significante y útil. Veamos, en primer lugar, las características de la definición $C$, que identifica la ideología con cualquier sistema simbólico que produce significación en relación con el poder y la configuración de la sociedad.

Tan ideológicos son los sistemas de creencias que tratan de conservar el orden social como los que propugnan su reforma o su revolución. Por tanto, estos autores conciben la ideología como todo sistema de creencias ordenado a la legitimación del poder, de la acción social y política en el sentido más amplio y general posible. Así, su concepción está directamente relacionada bien con una teoría del poder como fenómeno generalizado, bien con una teoría del poder como fenómeno restringido al campo o subsistema autónomo de lo político.

El poder puede ser definido de una forma amplia como un fenómeno generalizado: consiste en la capacidad para actuar en la consecución de objetivos e intereses particulares, la capacidad de intervenir en una secuencia de acontecimientos y alterar su curso. De acuerdo con dicha definición, podrían clasificarse dentro de esta categoría aquellas definiciones de la ideología para las cuales su función distintiva es la constitución de sujetos, de comunidades imaginarias o de identidades sociales.

Pero "poder» hace referencia también a la capacidad de acción en el ámbito específico de lo político, donde se dirime la configuración de la sociedad. Ideología designa, en este caso, el sistema de significaciones que conciernen a la organización social legítima, su funcionamiento y finalidades (ver Ansart, 
1974; Wilson, 1992). Así, por ejemplo, Ball y Dagger la defienen como «un conjunto de creencias bastante coherente y comprensivo que explica y evalúa las condiciones sociales, ayuda a la gente a comprender su lugar en la sociedad y proporciona un programa para la acción social y política» (1995: 9). Este es el uso que se ha impuesto entre los politólogos y los teóricos de los movimientos sociales (Laraña y Gusfield, 1994; Scott, 1990; Newman, 1995; Vincent, 1992). Para estos últimos, la ideología constituiría, junto con la estructura organizativa y la estrategia, uno de los elementos característicos de todo movimiento social (por ejemplo, la no violencia gandhiana sería un elemento de la ideología del movimiento de Martin Luther King, pero otro lo constituiría su mesianismo basado en el sueño americano fundacional).

Desde el punto de vista de la extensión, nos hallamos ante una concepción restrictiva — «sólo un tipo particular de creencias o aspecto de los sistemas de creencias son ideológicos»—, aunque tendencialmente universal — «todas las formas de legitimación de poder son ideología»—. Pero una vez dado ese salto hacia la neutralidad, algunos autores se preguntan: ¿por qué deberíamos restringir el campo del análisis ideológico en vez de ampliarlo a todas las formas de conocimiento y a todas las prácticas de significación? Así emerge la cuarta perspectiva.

\section{Concepción semiótica neutra: la ideología como sistema de creencias o como discurso}

En este apartado integramos una amplia diversidad de autores, tendencias, tradiciones e incluso disciplinas, cuyas definiciones son formuladas a partir de los años sesenta como consecuencia tanto del giro lingüístico como del giro hermenéutico. Aunque reservando posiciones muy distintas para los sujetos, ambos implican una consideración de las formas simbólicas no sólo como un elemento de la vida social que, como sostendrá el funcionalismo, responde a determinadas necesidades y cumple unas funciones concretas, sino como constitutivas de las relaciones y el mundo social: la sociedad es un universo preinterpretado, simbólicamente constituido, o, como dice Frow, todos los sistemas sociales son sistemas semióticos.

El aspecto general que comparten dichas concepciones es una universalización de la ideología, para lo cual desarrollan un concepto radicalmente nuevo: ideología es todo o cualquier sistema de creencias, pudiendo tener tanto una organización sistematizada y coherente como dispersa y heterogénea. Es un concepto central para entender los procesos de significación. Su locus propio es la teoría de la cultura.

Así, por ejemplo, la ideología, para Therborn, hace referencia a «ese aspecto de la condición humana bajo el cual los seres humanos viven sus vidas como actores conscientes en un mundo que cada uno de ellos comprende en diverso grado. La ideología es el medio a través del cual operan esta conciencia y esta 
significatividad»(1987: 1-2). O, como dice S. Hall: «aquellas imágenes, conceptos y premisas que proporcionan los marcos mediante los cuales representamos, interpretamos, comprendemos y producimos sentido de ciertos aspectos de la existencia social» (en Larrain, 1994: 73-74). Por tanto, la ideología sería una dimensión constitutiva de la sociedad y de la formación de la subjetividad humana, designaría los procesos de significación, los sistemas de creencias y de valores.

En el análisis suelen discernir dos planos: el meramente cognitivo y el de la práctica; la ideología como sistema de creencias que se poseen, como una categoría de la conciencia discursiva, y como proceso que se manifiesta en la experiencia de la vida cotidiana, en la conciencia práctica. Fruto de ello es la acuñación de conceptos como conciencia preteórica (fenomenología), mentalidad (historia de las mentalidades), prejuicio y representación social (Moscovici) y discurso (postestructuralismo).

Estas corrientes han supuesto una reacción razonable y sana frente a formas de análisis que reducían la cultura a un mero epifenómeno o que interpretaban las formas simbólicas como reflejo más o menos transparente de un mundo exterior dado. Pero también conducen al relativismo y disuelven toda posibilidad de crítica y evaluación. Tanto la tradición durkheimiana que considera que las formas simbólicas reflejan la realidad sin ocultarla, como el estructuralismo que postula el discurso como única fuente de constitución de lo social, abocan a la inconmensurabilidad de las formas de vida y de los valores. Si aceptamos sus postulados, nos quedamos huérfanos de criterios para analizar el error y el engaño, la injusticia y la dominación, y las ciencias sociales deberían enmudecer. De acuerdo con sus supuestos, resulta imposible tanto el análisis de la asimetría cultural (culturas contemporáneas con distinto grado de evolución) (sincronía) como de la irreversibilidad de determinados procesos culturales (diacronía) (la perspectiva en pintura, la circulación de la sangre en medicina, etc.). Y así, llevando la tesis al esperpento, podría sostenerse sin sonrojo que fue verdad, in illo tempore, que el sol giraba alrededor de la tierra (ver Norris, 1995).

En la medida, pues, en que dichas concepciones disuelven la totalidad social en el discurso, lo que sucede es que confunden órdenes o dimensiones de realidad: hay constitución simbólica, por supuesto, pero ¿por qué deberían excluirse otras prácticas sociales? $\mathrm{O}$, como ha planteado Larrain, "¿por qué deberíamos limitarnos a investigar lo que produce sentido en una ideología y no buscar también en ella lo que es incorrecto y exponerlo?» (1994: 83). Y, si aceptáramos que además de sentido también hay sinsentido, sentido correcto e incorrecto, verdadero y falso, justo e injusto, legítimo e ilegítimo, ¿por qué deberíamos confundir todo utilizando el término ideología para designar dichas realidades? En, desde y al mundo preconstituido, según nuestro punto de vista (ver figura 2), pueden dirigírsele distintas miradas y preguntas y se le puede constituir con perspectivas distintas que no se disuelven ni precipitan unas en otras. 


\section{FIGURA 2}

La diversidad de perspectivas sobre el universo preconstituido

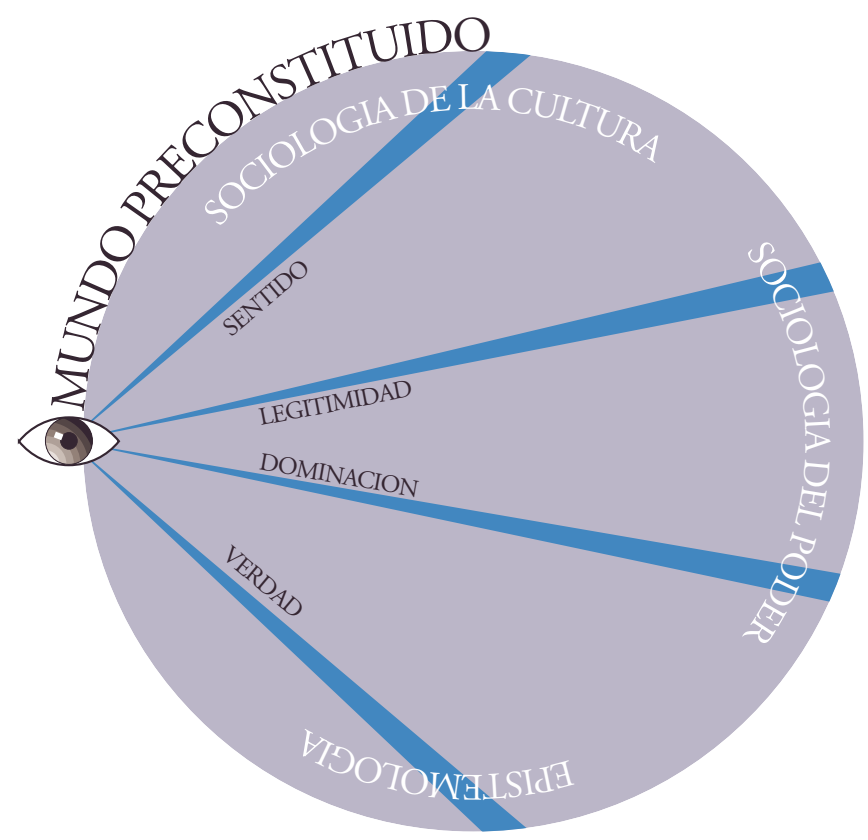

\section{IDEOLOGIAS Y DISCURSOS}

Desde luego, reconocer la diversidad de problemáticas no resuelve el dilema léxico, pero constituye el primer paso para ir acotando su alcance. De alguna manera, así está sucediendo en las recientes tendencias que se detectan en la bibliografía. Cuatro son especialmente pertinentes para el tema que nos ocupa:

1. Como consecuencia de los giros postempirista y hermenéutico, así como del desarrollo autónomo de la filosofía, historia y sociología del conocimiento científico, la concepción cognitivo-crítica, que contrapone ideología a ciencia y la identifica con prejuicio, error o ilusión, apenas tiene ya una presencia significativa.

2. Por el contrario, y como resultado de convergencias teóricas muy diferentes, se ha impuesto una concepción neutra restringida, político-neutra, que identifica ideología bien con cosmovisiones y teorías políticas, bien con los sistemas de creencias relativos a cualquier forma de poder y constitución de lo social (véase, por ejemplo, la reciente aparición del Journal of Political Ideologies). 
3. En ciertas corrientes teóricas (como el postestructuralismo) se ha producido incluso un abandono del término, reemplazándolo por el vocablo alternativo de discurso.

4. Sin embargo, ello no ha obstado para que también se desarrolle con fuerza una tendencia que trata de preservar un sentido crítico (sociopolítico crítico) y que pretende hacer compatible y complementario el análisis del discurso y el análisis de la ideología.

La decantación que se ha ido produciendo es muy reveladora, pues en algo parecen estar de acuerdo tanto los críticos como los neutros: en el tema de que tratan las ideologías. Estas se ocupan de los aspectos relativos a la configuración y la identidad del ser social, del poder en sentido tanto amplio como restringido. Quedan fuera, en buena lógica, el problema específicamente epistemológico (concepción cognitivo-crítica) y el problema semiótico (concepción cognitivo-neutra) y sólo se los toma en consideración en cuanto se hallan relacionados y afectan al tema central: la legitimidad del poder.

En este contexto, finalmente el dilema se reduce a si es posible y necesaria una evaluación de los sistemas de creencias relativos al poder, en qué términos, y si podemos nombrar adecuadamente ese proceso crítico como análisis de la ideología.

Nuestra propuesta es la siguiente. De forma esquemática, siguiendo a Sewell*, podemos representar en un diagrama (figura 3) la trama estructural de una sociedad como el resultado de la interacción de dos factores: los recursos y los esquemas culturales. En el eje horizontal ubicamos los esquemas/reglas, es decir, la cultura, y en el vertical los recursos sociales (poder, relaciones sociales, bienes materiales) que se distribuyen asimétricamente, de forma estratificada.

* Sewell, en un interesante artículo, parte de una crítica a la noción de estructura virtual de Giddens y a la noción de habitus de Bourdieu, para proponer una teoría alternativa que le permita incorporar a un tiempo el cambio en la estructura y superar la división entre las interpretaciones materialistas y semióticas. En este contexto, presenta su redefinición de la dualidad de la estructura: ésta se halla compuesta simultáneamente de esquemas, que son virtuales, y de recursos, que son reales, lo que implica que los esquemas son efectos de los recursos tanto como los recursos de los esquemas. "Una empresa no es un montón inerte de ladrillos, madera y metal. Incorpora o actualiza esquemas y esto significa que los esquemas pueden inferirse a partir de la forma material de la empresa. La entrada a la factoría, el lugar para fichar, el diseño de la línea de producción, todos estos rasgos de la empresa muestran y validan las reglas del contrato capitalista de trabajo» (1992: 13). En síntesis, nos dice Sewell, las estructuras están constituidas por esquemas culturales y conjuntos de recursos que se sostienen mutuamente, que capacitan y determinan la acción social y tienden a ser reproducidos por dicha acción. «Pero su reproducción nunca es automática. Las estructuras están en peligro, al menos en cierta medida, porque son múltiples y se entrecruzan, porque los esquemas son trasponibles y porque los recursos son polisémicos y acumulan impredecibilidad. Al situar la relación entre los recursos y los esquemas culturales en el centro de un concepto de estructura se hace posible mostrar cómo el cambio social, no menos que la estática social, puede ser generado por la realización de las estructuras en la vida social» (1992: 19). 


\section{FIGURA 3}

Las dimensiones de la estructura social y la interrelación entre ideologías y discursos (sentido e identidad)

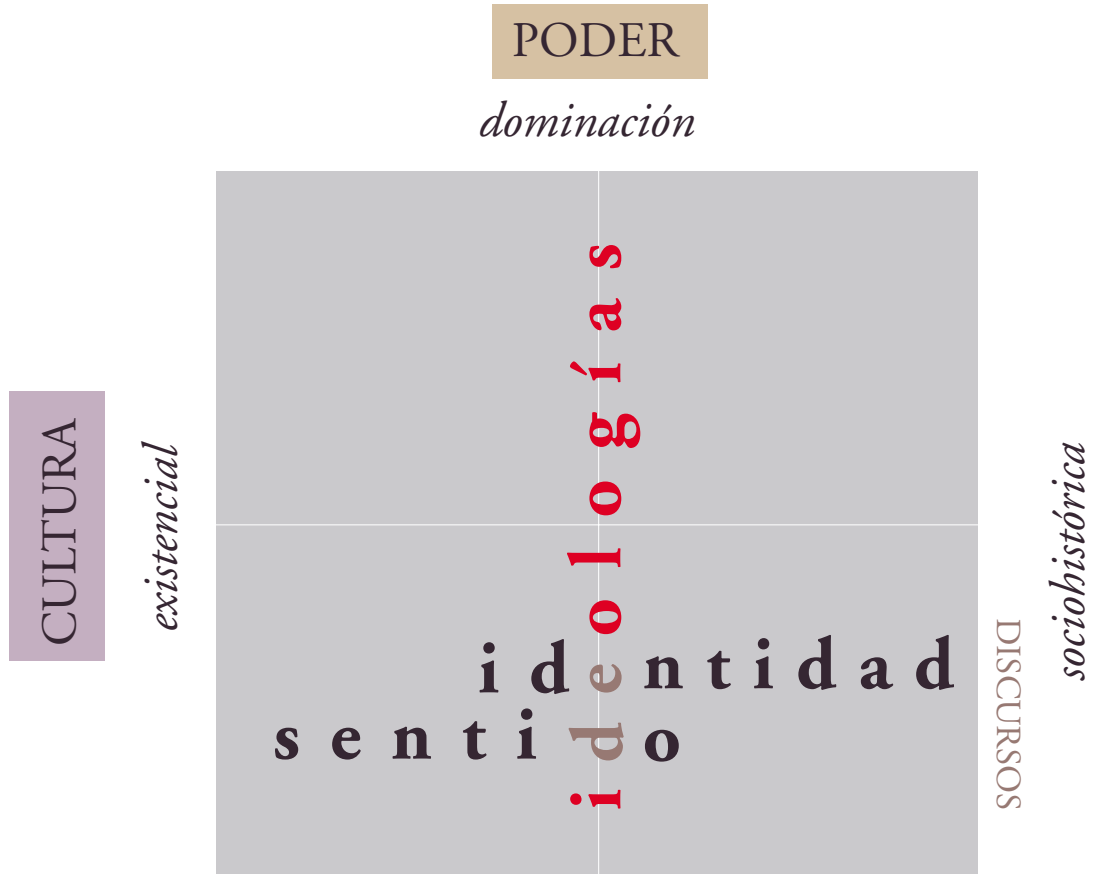

subordinación

La cultura (eje horizontal) produce tanto sentido (es decir, significado o sistemas de creencias y orientación o sistemas de valores) como identidad (constitución de sujetos personales o colectivos). Y proporciona significado tanto para las dimensiones meramente existenciales (como ser sexuado, ser mortal, tener una edad) como para las dimensiones sociohistóricas (pertenecer a una tribu o una nación, tener una u otra profesión, ser miembro de una iglesia, club, partido o movimiento). Para ello cuenta con visiones del mundo o cosmovisiones, que son sistemas de creencias articulados, y con narrativas, que son estructuras lingüísticas que exponen en forma de relato la trama de un conjunto de acontecimientos. Estos pueden ser fundantes o etiológicos (mito), ficticios (narración literaria) o referirse al pasado humano (narración histórica). Unas y otras, cosmovisiones y narrativas, proporcionan información de muy diversos tipos, unas y otras tienen componentes cognitivos y prácticos, unas y otras son formas de discurso. 
El discurso, tal y como lo entiendo aquí, depende de realidades extradiscursivas, a las que se refiere y significa; consiste tanto en textos como en prácticas, y su función es configurar identidades y posiciones sociales y producir conocimientos y creencias.

El poder y los recursos (eje vertical) se hallan distribuidos asimétricamente, lo que da la polaridad básica de dominación y subordinación. En su relación con la cultura pueden distinguirse al menos dos planos. Por un lado, el poder siempre está constituido semióticamente, de manera que poder y cultura se imbrican de forma indisoluble. Toda forma de poder comporta/produce conocimiento y toda forma de conocimiento comporta/produce poder. Pero, en un segundo plano, la cultura interrelaciona con el poder en tanto que consiste en sistemas de significado o formas simbólicas que legitiman la distribución de los recursos y la dominación. El dominio y el privilegio, si son duraderos, nunca se basan en la mera fuerza, requieren algún tipo de legitimación moral. En el primer sentido afirmamos que los movimientos sociales producen conocimiento e identidades alternativas con el propósito de transformar la realidad, y el conocimiento producido les capacita para desarrollar estrategias, formas de acción y construir nuevas identidades. En el segundo sentido observamos que los grupos dominantes producen una identidad cultural pública y la difunden con el propósito de legitimar y perpetuar su dominación.

Existe, pues, una vinculación intrínseca entre discurso y poder, que se da tanto en el plano de las cosmovisiones como en el de las narrativas de identidad. Podemos, en consecuencia, analizar y evaluar en qué medida las formas discursivas contribuyen a sostener, reestructurar, desafiar o transformar relaciones de poder. Mientras que los críticos proponen restringir el concepto de ideología a aquellas formas simbólicas que legitiman los poderes dominantes $\mathrm{u}$ ocultan las contradicciones sociales que les favorecen, los neutros, renuncien o no a la posibilidad de evaluación de las formas de poder y desigualdad, utilizan ideología para designar por igual los sistemas formales de ideas políticas y los sistemas informales de creencias y valores que movilizan para la acción social. Y dado que las pautas de comportamiento de los científicos sociales en relación con el léxico carecen de todo tipo de regulación formal, podemos sospechar que en el futuro las cosas seguirán como hasta el día de hoy.

Sin embargo, de acuerdo con el enfoque que hemos presentado (interrelación entre recursos y esquemas, estratificación y cultura, discurso y poder), creemos que existe espacio para un concepto crítico de ideología y que el análisis de la ideología debe gozar de legitimidad académica. En este caso, ideología y discurso serían complementarios. Mientras que éste designaría la totalidad de las estructuras lingüísticas y prácticas simbólicas mediante las cuales se produce sentido e identidad, ideología se referiría de forma restringida a aquellos aspectos del discurso que son utilizados contextualmente para legitimar relaciones de dominación del tipo que sean. Esta es la posición defendida por autores como Lincoln (1989), Dant (1991), J. B. Thompson (1992), Fairclough (1992), Purvis y Hunt (1993), Larrain (1994) o McLellan (1995). Las formas 
simbólicas no son per se intrínsecamente ideológicas. Son ambiguas, abiertas y contextuales; por ello mismo pueden ser instrumentalizadas para transformar el simple poder en autoridad o legitimar la dominación. Por ejemplo, el naturismo (figura 4) es una cosmovisión existencial, pero podría ser una ideología; el racismo es una narrativa existencial y una ideología; el nacionalismo es una cosmovisión, implica una narrativa y puede ser una ideología. Y lo mismo puede decirse del globalismo.

\section{FIGURA 4}

Ejemplificación de la contextualidad de las formas simbólicas y sus posibles funciones ideológicas

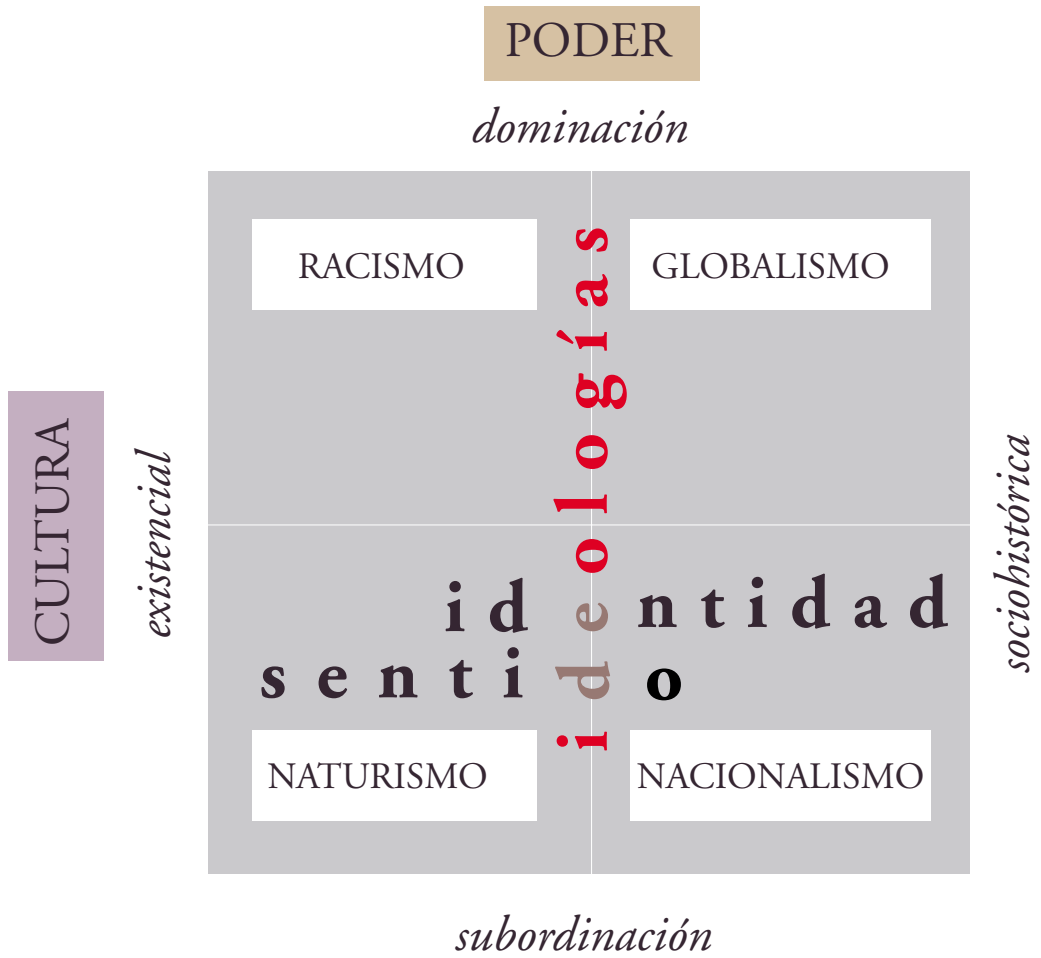

De acuerdo con esta concepción, el análisis de la ideología de lo que se ocupa es de la interrelación entre las prácticas discursivas y otras prácticas sociales; concretamente, de la relación entre la cultura y el poder. Y, por tanto, la ideología es sólo una de las posibles formas del discurso. 
Hemos comenzado con un ejemplo, concluiremos con otro. En esta ocasión nos referiremos a las representaciones sociales del dinero. Podría resultar de interés analizar visiones moralistas contrapuestas, como la popular del «vil metal» o la del «sentido reverencial del dinero» de Ramiro de Maeztu. Pero en un contexto de dogmatismo neoconservador (para el cual la libertad se identifica con ausencia de coerción física, la justicia distributiva con mera justicia en las transferencias, y el Estado debe quedar reducido a su mínima expresión), nos limitaremos a reproducir y comentar un fragmento de El dinero, de John K. Galbraith, donde trata acerca de la política monetaria:

«Los regímenes monetario y económico — afirma Galbraith— son parte inextricable del mayor problema de la distribución de la renta en la economía moderna. Esto será también cada vez más evidente. Nada más atractivo para el hombre de instinto conservador que la idea de que la política económica es una materia puramente técnica. No involucra cuestiones de clase social o de política social. Con la técnica adecuada se endereza la economía: el poder y la renta, y su disfrute, no resultan afectados. Tampoco los liberales han sido inmunes a la idea de que la política monetaria y fiscal son socialmente neutrales. Pero no es así. Como hemos visto, una de las características centrales de la sociedad económica moderna es el rechazo por las clases sociales subordinadas de los límites establecidos en su renta y su consumo... El movimiento hacia una distribución más conscientemente igualitaria de la renta tendrá que ser aspecto indispensable de una política económica fructífera» (1996: 297).

Aquí se nos describen dos clases de ideas: a) los supuestos acerca de la configuración de la sociedad actual (defensa de una sociedad más o menos igualitaria); b) las aserciones que legitiman las tesis neoconservadoras (interpretación de la política monetaria como una cuestión estrictamente técnica). Si aplicamos el término de ideología a las primeras, manejamos un concepto políticoneutro; si a las segundas, un concepto político-crítico, ya que analizamos uno de los modus operandi de la legitimación del privilegio.

Estoy persuadido de que, por un principio de economía léxica, se asentará y persistirá el uso neutro de ideología para designar sistemas de pensamiento sociopolítico y sistemas de creencias y valores de los movimientos sociales. Pero creo que el análisis ideológico, como desvelamiento de la utilización de las formas simbólicas al servicio de los privilegios y la dominación, puede y debe ocupar un lugar legítimo dentro de las ciencias sociales, mientras que para analizar sistemas de valores, sistemas de creencias y relatos de identidad son más adecuados conceptos como cosmovisión, narrativa y discurso. 


\section{BIBLIOGRAFIA CONSULTADA}

Abercrombie, N. (1982): Clase, estructura y conocimiento, Barcelona, Península.

Abercrombie, N.; Hill, S., y Turner, B. S. (1987): La tesis de la ideología dominante, Madrid, Siglo XXI.

Adorno, Th. W. (1971): La ideología como lenguaje, Madrid, Taurus.

Althusser, L. (1974): Escritos, Barcelona, Laia.

AMELANG, J. S. (1986): La formación de una clase dirigente: Barcelona 1490-1714, Barcelona, Ariel.

Ansart, P. (1974): Les idéologies politiques, París, PUF.

- (1990): Les sociologies contemporaines, París, Seuil.

Archer, M. (1988): Culture and Agency. The Place of Culture in Social Theory, Cambridge University Press.

ArIes, Ph. (1975): L'Enfant et la Vie Familiale sous l'Ancien Régime, París, Seuil.

Ball, T., y Dagger, R. (1995): Political Ideologies and the Democratic Ideal, Nueva York, Harper Collins College Publishers.

BAUdrillard, J. (1976): La génesis ideológica de las necesidades, Barcelona, Anagrama.

Bell, C. (1992): Ritual Theory, Ritual Practice, Nueva York, Oxford University Press.

BELL, D. (1982): Las contradicciones culturales del capitalismo, Madrid, Alianza.

- (1990): "The Misreading of Ideology: The Social Determination of Ideas in Marx's Works», en Berkeley Journal of Sociology, vol. 35, pp. 1-54.

- (1992): El fin de las ideologías. Sobre el agotamiento de las ideas políticas en los años cincuenta, Ministerio de Trabajo y SS.

BELLAH, R., et al. (1989): Hábitos del corazón, Madrid, Alianza.

Benton, T. (1981): Philosophical Foundations of the Three Sociologies, Londres, Routledge and Kegan Paul.

Berger, P., y Luckmann, T. (1986): La construcción social de la realidad, Buenos Aires, Amorrortu.

Berger, P.; Berger, B., y Kellner, H. (1979): Un mundo sin hogar. Modernización y conciencia, Santander, Sal Terrae.

BERgeron, L. (ed.) (1977): Niveles de cultura y grupos sociales, Madrid, Siglo XXI.

Billig, M. (1991): Ideology and Opinions. Studies in Rhetorical Psychology, Londres, Sage.

Boudon, R. (1989): The Analysis of Ideology, Polity Press.

- (1992): "Connaissance", en R. Boudon (dir.), Traité de Sociologie, París, PUF, pp. 491-532.

Bourdieu, P. (1972): Esquisse d'une theorie de la pratique, Geneve, Ed. Droz.

- (1979): La distinction, París, Minuit.

- (1980): Le sens pratique, París, Minuit.

- (1988): Cosas dichas, Buenos Aires, Gedisa.

- (1989): La noblesse d'état. Grandes écoles et esprit de corps, París, Minuit.

BourdieU, P., y PASSERON, J. C., (1977): La reproducción, Barcelona, Laia.

Bracher, K. (1984): The Age of Ideologies: A History of Political Thought in the Twentieth Century, Londres, Weindenfeld.

Cardano, M. (1990): "Il conflitto nei sistemi di credenze», en Rassegna Italiana di Sociologia, año XXXI, núm. 2, abril-junio, pp. 215-235.

CASTORIADIS, C. (1983): La institución imaginaria de la sociedad, 2 vols., Barcelona, Tusquets.

CHAZEL, F. (dir.) (1993): Action collective et mouvements sociaux, PUF.

Cortazzi, M. (1993): Narrative Analysis, Londres, The Falmer Press.

Cuco, J. (1982): «La cultura como dimensión de la realidad social», en M. García Ferrando (ed.), Pensar nuestra sociedad, Valencia, Gregal.

Cuvillier, A. (1971): Sociología de la cultura, Buenos Aires, El Ateneo.

DAnt, T. (1991): Knowledge, Ideology and Discourse. A Sociological Perspective, Londres, Routledge. 
Dhruvarajan, Vanaja (1989): Hindu Women and the Power of Ideology, Massachusetts, Bergin and Garvey Publishers.

Douglas, M. (1978): Símbolos naturales, Madrid, Alianza.

Dumont, F. (1963a): "Notes sur l'analyse des ideologies», en Recherches Sociographiques, vol. IV, núm. 2, pp. 155-165.

- (1963b): «Ideologie et savoir historique», en Cahiers Internationaux de Sociologie, vol. XXXV, julio-diciembre, pp. 43-60.

- (1974): Les idéologies, París, PUF.

Duby, G. (1976): Historia social e ideologías de las sociedades y otros ensayos sobre historia, Barcelona, Anagrama.

DURKHEIM, E. (1982): Las formas elementales de la vida religiosa, Madrid, Akal.

EAgleton, T. (1991): Ideology: An Introduction, Londres, Verso.

EATWell, R., y Wright, A. (1993): Contemporary Political Ideologies, Londres, Pinter.

ECO, U. (1977): Tratado de semiótica general, Barcelona, Lumen.

- (1978): La estructura ausente. Introducción a la semiótica, Barcelona, Lumen.

- (1990): Semiótica y filosofía del lenguaje, Barcelona, Lumen.

ELIAS, N. (1988): El proceso de la civilización, Madrid, FCE.

- (1990): La sociedad de los individuos, Barcelona, Península.

- (1994): Conocimiento y poder, Madrid, La Piqueta.

Eyerman, R. (1981): False Consciousness and Ideology in Marxist Theory, Stockhom, Almqvist and Wiksell and Humanities Press.

Fairclough, N. (1992): Discourse and Social Change, Polity Press.

Fierro, A. (1979): Sobre la religión. Descripción y teoría, Madrid, Taurus.

FouCAult, N. (1978): Vigilar y castigar. Nacimiento de la prisión, Madrid, Siglo XXI.

Frow, J. (1989): «Discourse and power», en M. Gane (ed.), Ideological Representation and Power in Social Relations, Londres, Routledge, pp. 189-217.

Fukuyama, F. (1990): «¿El fin de la historia?», en Claves para la Razón Práctica, núm. 1.

Gamble, A. (1984): revisión del libro de Larrain (1983), en Theory, Culture and Society, vol. 2, 2, pp. 139-141.

Gane, M. (ed.) (1989): Ideological Representation and Power in Social Relations, Londres, Routledge.

Geertz, C. (1987): La interpretación de las culturas, Barcelona, Gedisa.

GeIGer, T. (1972): Ideología y verdad, Buenos Aires, Amorrortu.

Gellner, E. (1989): Cultura, identidad y política, Barcelona, Gedisa.

Giddens, A. (1979): Central Problems in Social Theory, Londres, Macmillan Press.

- (1984): The Constitution of Society, Cambridge, Polity Press.

- (1989): Sociology, Cambridge, Polity Press.

Giner, S. (1985a): Sociología, Barcelona, Península.

- (1985b): Comunió, domini, innovació, Barcelona, Laia.

- (1987): Ensayos civiles, Barcelona, Península.

- et al. (1996): La cultura catalana: el sagrat i el profa, Barcelona, Edicions 62.

Gouldner, A. W. (1978): La dialéctica de la ideología y la tecnología, Madrid, Alianza.

GrisWold, W. (1994): Cultures and Societies in a Changing World, Londres, Sage.

Habermas, J. (1975): Problemas de legitimación en el capitalismo tardio, Buenos Aires, Amorrortu.

- (1981): La reconstrucción del materialismo histórico, Madrid, Taurus.

- (1982): Conocimiento e interés, Madrid, Taurus.

- (1984): Ciencia y técnica como ideología, Madrid, Tecnos.

- (1987): Teoría de la acción comunicativa, Madrid, Taurus.

- (1988): La lógica de las ciencias sociales, Madrid, Tecnos.

Hall, S. (1996): «Introduction: Who Needs'Identity?», en S. Hall y P. DU GaY, Questions of Cultural Identity, Londres, Sage, pp.1-17.

HARRIS, M. (1984): La cultura norteamericana contemporánea: una visión antropológica, Madrid, Alianza. 
Heywood, A. (1992): Political Ideologies: An Introduction, Londres, Macmillan.

HONDERICH, T. (1990): Conservatism, Londres, Hamilton.

Horkheimer, M., y Adorno, Th. (1971): Dialéctica del iluminismo, Buenos Aires, Sur.

Horowitz, I. L. (1977): Ideology and Utopia in the United States 1956-1976, Londres, Oxford University Press.

Huber, J., y Form, W. H. (1973): Income and Ideology. An Analysis of the American Political Formula, Nueva York, Free Press.

IbÁÑEZ, T. (ed.) (1988): Ideologías de la vida cotidiana, Barcelona, Sendai.

Jerez MiR, R. (1990): Marx y Engels: el marxismo genuino, Madrid, Cincel.

JODELET, D. (ed.) (1989): Les representations sociales, París, PUF.

LARAÑA, E., y GusField, J. (1994): Los nuevos movimientos sociales. De la ideología a la identidad, Madrid, CIS.

LARRAIN, J. (1983): Marxism and Ideology, Macmillan.

- (1994): Ideology and Cultural Identity. Modernity and the Thrid World Presence, Polity Press.

LAYDER, D. (1994): Understanding Social Theory, Londres, Sage.

LEACH, E. (1978): Cultura y comunicación. La lógica de la conexión de los símbolos, Madrid, Siglo XXI.

LENK, K. (1974): El concepto de ideología, Buenos Aires, Amorrortu.

LensKi, G. (1969; e. o., 1966): Poder y privilegio, Buenos Aires, Paidós.

LenSKI, G., y LeNSKI, J. (1970): Human Societies. An Introduction to Macrosociology, McGraw Hill.

LEWINS, F. (1989): «Recasting the concept of ideology; a content approach», en The British Journal of Sociology.

LEWIS, J. (1991): The Ideological Octopus. An Exploration of Televison and His Audience, Londres, Routledge.

Lichtheim, G. (1972): El concepte de ideologia, Valencia, Tres i Quatre.

Lincoln, B. (1989): Discourse and the Construction of Society. Comparative Studies of Myth, Ritual and Classification, Oxford University Press.

LIPSET, S. M. (1977): El hombre politico, Buenos Aires, Universitaria.

Lotman, J. M., et al. (1979): Semiótica de la cultura, Madrid, Cátedra.

Mannheim, K. (1966): Ideología y utopia, Madrid, Aguilar.

- (1990): El problema de una sociología del saber, Madrid, Tecnos.

MARCUSE, H. (1971): El hombre unidimensional, Barcelona, Seix Barral.

MARX, K. (1970): Contribución a la crítica de la economía política, Madrid, A. Corazón.

- (1971): El Capital, 3 vols., México, FCE.

- (1973): Miseria de la filosofía, Madrid, Aguilar.

- (1974): Manuscritos: economía y filosofía, Madrid, Alianza.

MARX, K., y ENGELS, F. (1972): La ideología alemana, Barcelona, Grijalbo.

- (1974): Sobre la religión, Salamanca, Sígueme.

McLellan, D. (1995, 2. a ed.): Ideology, Buckingham, Open University Press.

Morales, J., y ABAD, L. V. (1988): Introducción a la sociología, Tecnos.

Morin, E. (1992): El Método. Las ideas, Madrid, Cátedra.

MosCA, G. (1984; 1. a ed., 1896): La clase politica, México, FCE.

MuÑoz, B. (1989): Cultura y comunicación, Barcelona, Barcanova.

NAMER, G. (1985): Court traité de sociologie de la connaissance, París, Méridiens.

- (1987): Memoire et societé, París, Méridiens.

Newman, D. M. (1995): Sociology. Exploring the Architecture of Everyday Life, Londres, Pine Forge Press.

NorRIS, C. (1995): «Truth, Science andthe Growth of Knowledge», en New Left Review, 210, pp. 105-123.

Oltra, B. (1983): «El proceso de la ideología», en J. F. Marsal y B. Oltra (eds.), Nuestra sociedad. Introducción a la sociología, Barcelona, Vicens.

ORTEGA Y GASSET, J. (1977): Ideas y creencias, Madrid, Revista de Occidente.

- (1979): Sobre la razón histórica, Madrid, Alianza. 
Purvis, T., y HunT, A. (1993): «Discourse, ideology, discourse, ideology, discourse, ideology...", en British Journal of Sociology, vol. 44, núm. 3, septiembre, pp. 473-499.

Reboul, O. (1986): Lenguaje e ideología, México, FCE.

Ribgbey, B. (1991): Popular Culture in Modern France. A Study of Cultural Discourse, Routledge.

RiESSMAN, C. K. (1993): Narrative Analysis, Londres, Sage.

Rodríguez Aramberri, J. (1984): «Las ideologías», en S. del Campo (ed.), Tratado de sociologia, Madrid, Taurus.

Rodríguez Paniagua, J. M.a (1972): Marx y el problema de la ideología, Madrid, Tecnos.

Rosen, M. (1996): On Voluntary Servitude. False Consciousness and the Theory of Ideology, Polity Press.

Rossi-Landi, F. (1980): Ideología, Barcelona, Labor.

RuDE, G. (1981): Revuelta popular y conciencia de clase, Barcelona, Crítica.

SÁNCHEZ DE ORCAJO, J. J. (1979): La cultura. Reproducción o cambio, Madrid, CIS.

Schroeder, R. (1992): Max Weber and the Sociology of Culture, Londres, Sage.

SCIOlla, L. (1989): "L'adozione di credenze», en Rassegna Italiana di Sociologia, año XXX, núm. 2, abril-junio, pp. 239-266.

ScotT, A. (1995): Ideology and the New Social Movements, Londres, Routledge.

SEIDMan, S. (1989): "Constructing Sex as a Domain of Pleasure and Self-expression: Sexual Ideology in the Sixties», en Theory, Culture and Society, 6, pp. 293-315.

SHILS, E. (1974): «Ideología. Concepto y función», en Enciclopedia Internacional de las Ciencias Sociales, pp. 599-607.

STRINATI, D. (1995): Introduction to Theories of Popular Culture, Londres, Routledge.

Therborn, G. (1987): La ideología del poder y el poder de la ideología, Madrid, Siglo XXI.

Thompson, J. B. (1984): Studies in the Theory of Ideology, Cambridge, Polity.

- (1992): Ideology and Modern Culture, Cambridge, Polity.

Thompson, K. (1986): Beliefs and Ideology, Londres, Ellis Horwood Limited-Tavistock Publications.

- (1992): «Religion, values and ideology», en R. BoccoK y K. THOMPson, Social and Cultural Forms of Modernity, Polity.

TURner, B. S. (1991): Religion and Social Theory, 2. a ed., Londres, Sage.

VARIOS (1982): Análisis estructural del relato, Barcelona, Ediciones Buenos Aires.

- (1984): Sobre el concepto de cultura, Barcelona, Mitre.

- (1993): Ideologías políticas, Madrid, Tecnos.

Veron, E. (comp.) (1973): El proceso ideológico, Buenos Aires, Tiempo Contemporáneo.

Vincent, A. (1992): Modern Political Ideologies, Oxford, Blackwell.

VOVElle, M. (1982): Ideologies et mentalités, París, Maspero.

WAters, M. (1994): Modern Sociological Theory, Londres, Sage.

WernicK, A. (1983): «Advertising and Ideology: An Interpretative Framework», en Theory, Culture \& Society, vol. 2, núm. 1.

Williams, R. (1966): Culture and Society 1780-1950, Penguin Books.

- (1980): Marxismo y literatura, Barcelona, Península.

- (1981): Keywords. A Vocabulary of Culture and Society, Londres, Fontana.

- (1982): Cultura. Sociología de la comunicación y del arte, Buenos Aires, Paidós.

Wilson, R. W. (1992): Compliance Ideologies, Cambridge University Press.

Wilson, T. (1993): Watching Television: Hermeneutics, Reception and Popular Culture, Polity.

Wuthnow, R. (1989): Communities of Discourse. Ideology and Social Structure in the Reformation, the Enlightenment, and European Socialism, Harvard University Press.

Wuthnow, R.; Hunter, J. D.; Bergesen, A., y Kurzweil, E. (1988): Análisis cultural. La obra de Peter L. Berger, Mary Douglas, Michel Foucault y Jürgen Habermas, Buenos Aires, Paidós.

Wolf, K. (1974): Contribución a una sociología del conocimiento, Buenos Aires, Amorrortu.

Wolf, M. (1988): Sociologías de la vida cotidiana, Madrid, Cátedra.

YANUZZI, M. ${ }^{a}$ de los A. (1993): Intelectuales, masas y élites. Una introducción a Mosca, Pareto y Michels, Rosario (Argentina), UNR (Facultad de Ciencia Política y Relaciones Internacionales). 


\begin{abstract}
This paper aims to effect a critical revision of the prolific literature that exists on the subject of ideologies. The author explores a field of the social sciences, more particularly that of the sociology of culture, in which essay-writing and lexical polysemy abound, with a view to imposing analytical rigour. To this end, a typology of the main conceptions of ideology is built, differentiating between four large conceptual models: cognitive-critical, political-critical, politicalneutral and semiotic. After describing and examining each of these conceptions at length, the author opts for a political-critical conception which restricts the field of ideology analysis to the use of symbolic forms in contexts of power and for the purpose of legitimation. Meanwhile, this approach involves redefining concepts such as discourse, cosmovision and narrative.
\end{abstract}

